\title{
Editorial
}

\section{How the Covid-19 pandemic has affected, and will affect, operations and supply chain management research and practice}

\section{Introduction}

The Covid-19 pandemic has caused significant impacts at all levels - societal, organisational and personal. At the time of writing, there has been a significant death toll worldwide with many nations still gripped by restrictions put in place to mitigate the impact of the virus. Some countries are beginning to recover, although the impacts will be felt for many years. Rather than writing a reflection piece on the EurOMA conference that was held virtually in 2020, we thought it best to consider how the pandemic has impacted research and practice in operations and supply chain management (OSCM).

The pandemic has undoubtedly changed the ways we live and work and has brought to the fore the importance of effectively managing operations and supply chains not only to scholars and specialists but also to the layperson. Significant interest, for example, has been demonstrated towards the process of developing, scaling-up and administering vaccines or towards the failure of medical and retail supply chains to deal with unprecedented demand from patients and customers.

In this editorial, we focus on three main types of implications that Covid-19 has had and will have for OSCM theory and practice:

(1) Reinforcing the importance of existing topics such as collaboration in supply chains.

(2) Accelerating the adoption of certain practices in various areas including new product development and digital transformation.

(3) Questioning some approaches, such as the implementation of lean in times of volatility and uncertainty, and giving the opportunity to investigate further ones in relation to complex supply chains, strategy implementation and people management.

In the next sections, we first identify several themes and potentially fruitful avenues for future scholarly enquiry. Subsequently, we introduce the papers selected for this special issue.

\section{Themes whose importance has been reinforced by Covid-19}

One of the clear impacts upon supply chains and operations wrought by Covid-19 was the unprecedented and unpredictable demand that caused scarcity of products. This misalignment of demand with supply-side capacity and capability had several significant effects. One of the most publicised supply chain challenges at the start of the pandemic was the global shortage of personal protective equipment (PPE) due to the massive increase in demand. This created a hyper-competitive market with both buyers and sellers behaving with naked self-interest leading to price gouging $(\mathrm{OECD}, 2020)$. This behaviour is expected in times of crises, but how

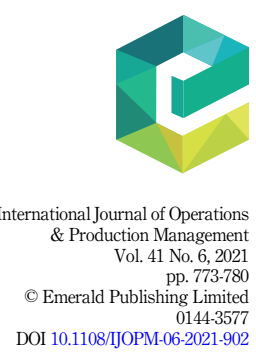


IJOPM 41,6

did we get to the situation? In the UK, for example, spending on PPE increased over a hundredfold, from $£ 146 \mathrm{~m}$ in 2019 to $£ 15 \mathrm{bn}$ in 2020 (NAO, 2020). While part of this increase was due to inadequate government policy and decentralised procurement practices, there remains the simple fact that many countries did not have local PPE production capability and were exposed to an extremely volatile market. PPE, like most goods perceived to be low value, is produced in low-cost economies with the resultant hollowing out of capacity in higher-cost countries. With a reduction of capacity comes, over time, a withering of capability and knowledge to produce these goods. This capability is not just related to production but also to product and process design as well as research and development. Collectively, these issues are what Pisano and Shi (2009) refer to as "the industrial commons." If we want to learn from what has happened over the last 18 months, to deal with changes in demand caused by exogeneities such as pandemics, all actors within a network will need to be coordinated. This will require interventions at a policy level to identify, support and nurture capability and capacity also in sectors that were previously viewed as unimportant.

While much of the research that is beginning to emerge from OSCM scholars focuses on resilience and fragility in supply chains, we believe that some of the solutions to future "black swan" events lie in identifying and strengthening strategic capabilities. PPE is relatively simple to manufacture; however, there are some materials within it that are rather advanced, such as certain types of plastic films. In the movement towards reducing the consumption of single-use plastics, such as carrier bags, there had been a reduction in the capacity to produce films in European countries. The significant increase in demand for PPE that used film required some firms to establish indigenous supply chains from scratch with one firm building a plastic film supply chain in three weeks (Davies, 2020). This example highlights the importance of identifying exactly what capacity and capability needs to exist to supply critical items, such as PPE, and whether these should be on-shored.

In addition to demand and supply challenges during the worst times of the crisis, difficulties also exist now that we are (hopefully) in the early stages of recovery. Consider the garment industry, which is underpinned by highly adversarial relationships between the retailer and manufacturer and with retailing being done traditionally through stores. When stores closed due to the pandemic, demand dried up. Brands and stores that sell own-brand garments stopped demand and imposed punitive terms upon suppliers. These were then passed onto their sub-contractors and suppliers. These sub-contractors and suppliers in turn transitioned their capacity, resources and capabilities towards the production of PPE, a market where there was demand. Now that the demand for garments is increasing as economies open, it is more difficult for buyers to procure them due to the increased profits from PPE and the adversarial approach that buyers had previously adopted. Also, when garments can be procured, shipping them from countries such as Bangladesh, Cambodia and Vietnam has become prohibitively expensive with the cost increasing from $\$ 2,000$ per 40 foot shipping container to over $\$ 7,000$ for a landed load on the West Coast of the USA. Thus, while production capacity may be available, logistics capacity may hinder the interconnectedness of supply chains. Drawing on these phenomena, promising questions for future research include

(1) When considering the alignment of demand with supply-side capacity and capability, how can we make the "industrial commons" work?

(2) Post-Covid, how can we decide which capacities and capabilities to on-shore?

(3) What is the role of various stakeholders, including governments, in identifying and strengthening strategic capabilities?

(4) Also, when and how should visibility and transparency across the supply chain be promoted? 


\section{Changes in practices accelerated by Covid-19}

Besides reinforcing the importance of certain topics and themes, the pandemic has also promoted the faster diffusion of various practices in relation to new product development processes, open innovation, digital transformation and changes in the nature of consumption. While reducing time to market has been a priority in many industries, the success of vaccine development attained by some pharmaceutical firms has been spectacular, compressing the period from the start of clinical testing (Phase 1) to drug approval from an average of ten years to less than one (Agrawal et al.,2021). This has been possible thanks to the execution in parallel or the merger of new product development phases and the concurrent acceleration in granting approvals by regulatory bodies. Future research could distil key learning points from these experiences and address questions such as

(1) How can new product development processes be reshaped in various industries?

(2) How can regulators play a positive role in reducing time to market while not compromising on product quality and safety?

The fast development of vaccines also highlights the importance of openness and collaboration among organisations when innovating: many of the vaccines that were approved first are the result of the joint efforts of two or more organisations (ABPI, 2021). Pre-Covid, some companies had begun investing in the development of business ecosystems to access a broad range of resources, become more flexible and resilient and deliver increasingly complex products and services (Shipilov and Gawer, 2020). This trend is likely to accelerate post-pandemic; however, lots of questions still have to be addressed, for example

(1) How will product and service development processes change across organisations?

(2) How will new collaborative agreements be created?

(3) What will be the implications, for example in relation to the sharing of resources and of intellectual property rights?

The necessity to reduce physical interactions during the pandemic has also boosted digital transformation in its different forms, leading to the adoption of new channels of communication with various stakeholders, most notably customers. Examples abound from retail banking and insurance where digital channels have almost entirely replaced in-person interactions, to healthcare where telemedicine has been greatly sped up (Stokel-Walker, 2020) and to higher education where many online and blended programmes have been launched over the last year alone. In these and other settings, new channels of communications are likely to stay and become the norm. Future studies could focus on the following questions:

(1) How will the use of new channels affect service design and delivery processes?

(2) How will the digitisation of many processes within and across organisations be managed?

(3) Will digitisation help revive investments in business analytics, particularly in relation to customer engagement (Ransbotham and Kiron, 2018)?

When the mass closure or restriction on access to stores and hospitality began in early 2020, a significant number of consumers turned to the Internet to buy goods. Companies such as Amazon saw significant increases in sales, while the takeaway fast-food market also grew rapidly. There is some debate about whether this change is leading to a "new normal" or consumers will seek to return to "old ways." Nonetheless, greater uptake of takeaway (Lock, 2021), for example, will present a pressing choice, especially for chains, over whether to 
IJOPM 41,6 outsource the customer order platform and delivery fulfilment or to perform these activities in-house (or to adopt a hybrid). Questions for future research include

(1) How will these and other outsourcing decisions be made?

(2) How will capacity be managed and last mile delivery improved?

\section{Need for alternative approaches}

As discussed above, the pandemic has highlighted the interconnectedness of supply chains which, in the future, may demand that less adversarial relationships be developed between partners, also in settings where decisions have traditionally been cost-driven. A pertinent example is represented by the shortage of microchips that, at the time of writing, is hindering automakers' capacity to restart production (Fleming et al., 2021; Naughton, 2020). Automakers have often adopted a "beggar thy neighbour" approach where suppliers are treated in an antagonistic way (cf. Liker and Choi, 2004) and where the focus has been on a sub-system (the automakers' supply chains) rather than the wider system, i.e. the global network that produces and consumes microchips. This is particularly problematic, as automakers purchase relatively small volumes of chips compared to consumer electronics firms, for example. Indeed, the adversarial approach coupled with limited purchasing power has left automakers struggling to buy chips, leading to production delays and plant shutdowns in the light of significant increases in demand for consumer electronics products, such as the Sony PlayStation 5. This example clearly illustrates how fluctuations in demand in one industry can have a significant effect in a seemingly disconnected industry. Firms therefore need to be cognisant of the wider supply networks in which they operate, which is no small feat (cf. Choi and Hong, 2002) due to the complexity and dynamics of the whole network. This complexity requires the adoption of a system of systems approach by firms, governments and international institutions (Fleming et al., 2021); promising questions for future studies include

(1) How can wider networks and systems be identified and studied (see Son et al. (2021))?

(2) Which strategies can be put in place to manage interdependencies in a complex system?

(3) What are the roles that various actors (private and public) could play?

The pandemic has illustrated that JIT supply chains can be incredibly fragile and easily disrupted. In several instances over the past year, we have witnessed reductions in capability, capacity and supply caused by interruptions to suppliers in conjunction with changes in demand. As a consequence, various automotive manufacturers have begun to move away from JIT supply chains to create more "antifragile" (cf. Taleb, 2012) networks that are more responsive to significant changes in demand, capacity or supply. Such events have called into question the benefits of adopting various process improvement approaches such as lean. Several commentators have emphasised that, post-pandemic, standard work, for example, may be required for organisations to be as efficient as possible in the way they use limited resources and to create the baseline for further improvement (De Smet et al., 2020). However, the need to ensure flexibility and speed challenges some of the slow, incremental improvements that lean normally delivers. Changes in how the trade-off between efficiency and resilience is regarded are likely to lead to substantial changes in practices. For example, healthcare providers have been urged to rethink their inventory management strategies, which are geared towards cost efficiency to avoid the shortages of critical supplies (Patrinley et al., 2020). Future research could address the following questions: 
(1) How will the focus on resilience and flexibility impact the perception of lean and other process improvement approaches?

(2) What are the effects of standardisation and control in dynamic environments?

Over the last year, many organisations, especially large ones, have had to adopt very emergent approaches to strategy development and implementation, in contrast with traditional plan-and-execute ones. This has also challenged political and business leaders' propensity to set specific targets even when many aspects are unknown - a clear example being the UK Government's decision to set a roadmap towards "freedom" well in advance of the pandemic being over, thus leading to conflicting messages to the population. At an organisational level, a more emergent approach has also resulted in de-prioritising or even scrapping strategic plans often leaving employees without the typical tools that contribute to create a sense of direction (e.g. objectives, performance indicators, targets and rewards). Future studies could address the following questions:

(1) How can a clear sense of direction be established in presence of increasing ambiguity and dynamism?

(2) Is alignment within and across organisations still a useful concept in OSCM?

The pandemic has had profound effects on the ways we work, and this has and will have significant consequences on how we manage operations. For example, some organisations have coupled flexible and remote working with agile ways of operating (Handscomb et al., 2020). In hospitals, greater agility has also resulted in work scheduling and reconfigurations of spaces and flows of patients to better address fluctuations in demand. Furthermore, while the automation of certain tasks has been traditionally introduced to improve standardisation and reduce cost, with Covid, investments in automation have increased also because of concerns with worker safety and well-being (transmission of the virus). This is not happening just in factories or warehouses but also in customer-facing roles in restaurants and hotels, for instance. Therefore, future research could investigate the following questions:

(1) How do changes in work patterns affect the ways in which we manage operations?

(2) How is greater agility in the workplace impacting operational processes?

(3) How are investments in automation affecting employees' safety and well-being?

While these reflections and questions are by no means exhaustive, we hope they will stimulate research that will not regard the Covid-19 pandemic as an "interference" of an otherwise linear trajectory, but rather as a turning point, partly in relation to the adoption of specific practices, partly in relation to potentially considerable and long-lasting shifts in managers' perceptions. While OSCM researchers and management scholars more broadly have investigated a number of trade-offs and paradoxes, Covid-19 may have shifted the balance between elements, thus resulting in changes in decision-making patterns. For instance,

(1) How has Covid-19 altered the perception of the trade-off between efficiency and resilience or between alignment and adaptability?

(2) Since Covid-19 has made us question our capacity to reliably forecast future events, will there be a much increased focus on agility and flexibility in the future?

While we are undoubtedly, for better or worse, living in interesting times, we are also witnessing a period where OSCM-related issues are at the forefront of everybody's minds. We 
IJOPM 41,6

should not waste the opportunity to conduct impactful research that can truly change the world.

\section{Articles included in this special issue}

It is our pleasure to introduce the nine articles selected for this special issue. While all these studies were conducted before the pandemic, some themes identified above are also discussed in these manuscripts. Below, we briefly present the articles in thematic order.

Son et al. (2021) focus on the effects of the 2011 Tohoku earthquake and tsunami in Japan on firms' supply network structures. While the empirical context is different from the one of the Covid-19 pandemic, results are relevant for the current situation. In particular, these authors show that firms affected by the 2011 earthquake experienced changes in their supply network structures, moving towards networks with lower complexity. Balthu and Clegg conduct an action research-based intervention, which involves the use of systems thinking, in a professional service environment. They find that there is potential for rationalising processes and service delivery commodification, mainly in the low volume, high variety legal service typology. Related to this, the study conducted by Ates and Memis investigates supply base complexity, an issue that we regard as increasingly salient, as mentioned in our reflections above. Drawing on survey data collected from 209 firms, the authors conclude that supply base complexity is not always detrimental and that OSCM practitioners should aim to ensure high levels of strategic purchasing in order to mitigate the negative effects of supply base complexity, while exploiting its benefits.

Chedid et al. use supply network and internal network data to examine the interactions between supply and internal networks in the context of multinational corporations. As these authors rightly point out, large firms tend comprise complex, geographically dispersed business units and subsidiaries and therefore should be conceptualised as such rather than as single entities. This study highlights the challenges of managing a complex subsidiary network and find that the performance effect of physical proximity of the firm with its supply network is negatively moderated by the geographic dispersion of the firm's internal network.

In total, two studies focus on environmental issues in supply chain management. Adopting a paradox perspective, Zehendner $e t$ al. examine sustainability tensions in the electronics supply chain. They find that four elements (learning, belonging, organising and performing) can conflict with sustainability goals. Moreover, they show that these elements interact and can reinforce each other, but managers can reduce sustainability tensions by contextualising paradoxes internally and externally. Somewhat related, Nath and Ewe investigate multi-tier supply chains from a sustainability point of view. Using institutional theory, they identify three different institutional logics - market-led, values-led and holistic sustainability - that are perceived to either conflict or complement the implementation of sustainability practices in the supply chain. This study emphasises how different logics lead to the enactment of different responses to institutional pressures.

In total, two studies concentrate on kaizen, at individual and team levels. Yokozawa et al. examine the role of anxiety in kaizen behaviour and performance by empirically testing the influence of personal anxiety (state and trait) on individual kaizen behaviours (rule adherence, initiative and perseverance of effort), which, in turn, affect individual kaizen performance. Results show that state anxiety has a significantly positive effect on rule adherence and kaizen performance. Trait anxiety positively influences employees' initiative and perseverance but has a significant negative effect on kaizen performance.

Using mixed methods, Franken $e$ al. examine Kaizen event meetings with the aim of enhancing their quality. In particular, they find that some of the groups they studied spent too little time on a group-shared understanding of the problem and its root causes and that, instead, explicit group consensus is crucial for the success of these events. Also, small and 
infrequent deviations to another phase appear necessary for a high-quality process. Using their newly developed quantitative process measure, these authors conclude that when groups tend to jump from one phase to a distant, previous or next phase, this relates to low Kaizen event process quality.

Finally, Guldenpfennig et al. draw on the management control systems (MCSs) as a package literature to investigate the joint use and effects of multiple MCSs involved in productivity improvement at a global automotive supplier. They find that a wide range of MCSs are involved in productivity improvement programmes; illustrate complementary and conflicting relationships among the various MCSs and show how managers rely on a set of mechanisms to alleviate tensions and strengthen complementarities among the MCSs used.

The study concludes by highlighting some good practices and learning from the application of action research and two tools - the $\mathrm{PrOH}$ modelling methodology and the Change Kaleidoscope.

\section{Pietro Micheli, Mark Johnson and Janet Godsell}

\section{References}

ABPI (2021), available at: https://www.abpi.org.uk/medicine-discovery/covid-19/what-arepharmaceutical-companies-doing-to-tackle-the-disease/\#dac06ec7 (accessed 23 July 2021).

Agrawal, G., Hermann, R., Møller, M., Poetes, R. and Steinmann, M. (2021), "Fast-forward: will the speed of COVID-19 vaccine development reset industry norms?", McKinsey report (accessed 13 July 2021).

Choi, T.Y. and Hong, Y. (2002), "Unveiling the structure of supply networks: case studies in Honda, Acura, and DaimlerChrysler", Journal of Operations Management, Vol. 20 No. 5, pp. 469-493.

Davies, R. (2020), “Government 'Ignores' UK textiles firms desperate to make PPE”, The Guardian, London (accessed 16 April 2020).

De Smet, A., Pacthod, D., Relyea, C. and Sternfels, B. (2020), "Ready, set, go: reinventing the organization for speed in the post-COVID-19 era", McKinsey report (accessed 26 June 2020).

Fleming, S., Hollinger, P. and Hall, B. (2021), "Semiconductors: Europe's expensive plan to reach the top tier of chipmakers", Financial Times (accessed 21 July 2021).

Handscomb, C., Mahadevan, D., Schor, L., Sieberer, M., Naidoo, E. and Srinivasan, S. (2020), "An operating model for the next normal: lessons from agile organizations in the crisis", McKinsey report (accessed 25 June 2020).

Liker, J.K. and Choi, T.Y. (2004), "Building deep supplier relationships", Harvard Business Review, Vol. 82 No. 12, pp. 104-113.

Lock, S. (2021), "Digitalization of the restaurant industry - statistics and facts", Statista, available at: https://www.statista.com/topics/8103/digitalization-of-the-restaurant-industry/ (accessed 18 June 2021).

NAO (2020), The Supply of Personal Protective Equipment (PPE) during the COVID-19 Pandemic, National Audit Office, London.

Naughton, J. (2020), "Why a silicon chip shortage has left carmakers in the slow lane", The Guardian, London (accessed 5 June 2021).

OECD (2020), "The face mask global value chain in the COVID-19 outbreak: evidence and policy lessons", available at: https://www.oecd.org/coronavirus/policy-responses/the-face-mask-globalvalue-chain-in-the-COVID-19-outbreak-evidence-and-policy-lessons-a4df866d/.

Patrinley, J., Berkowitz, S., Zakria, D., Totten, D., Kurtulus, M. and Drolet, B. (2020), "Lessons from operations management to combat the COVID-19 pandemic", Journal of Medical Systems, Vol. 44 No. 7, p. 129. 
IJOPM

41,6

780
Pisano, G.P. and Shih, W.C. (2009), "Restoring American competitiveness", Harvard Business Review, Vol. 87 Nos 7/8, pp. 114-125.

Ransbotham, S. and Kiron, D. (2018), "Using analytics to improve customer engagement", MIT Sloan Management Review, Findings from the 2018 Data and Analytics Global Executive Study and Research Report.

Son, B.G., Chae, S. and Kocabasoglu-Hillmer, C. (2021), "Catastrophic supply chain disruptions and supply network changes: a study of the 2011 Japanese earthquake", International Journal of Operations and Production Management, Vol. 41 No. 6, pp. 773-780.

Shipilov, A. and Gawer, A. (2020), "Integrating research on interorganizational networks and ecosystems", Academy of Management Annals, Vol. 14 No. 1, pp. 92-121.

Stokel-Walker, C. (2020), "Why telemedicine is here to stay", BMJ, p. 371, doi: 10.1136/bmj.m3603.

Taleb, N.N. (2012), Antifragile: Things that Gain from Disorder, Random House Incorporated, Vol. 3. 